\title{
GCU
}

Glasgow Caledonian

University

University for the Common Good

\section{Towards a novel optical trace oxygen sensor for commercial use}

McDowell, G. R.; Farrow, F. G.; Uttamlal, M.; Holmes-Smith, A.S.; Mitchell, C.; Shannon, P.H.

Published in:

2016 IEEE SENSORS

DOI:

10.1109/ICSENS.2016.7808789

Publication date:

2017

Document Version

Author accepted manuscript

Link to publication in ResearchOnline

Citation for published version (Harvard):

McDowell, GR, Farrow, FG, Uttamlal, M, Holmes-Smith, AS, Mitchell, C \& Shannon, PH 2017, Towards a novel optical trace oxygen sensor for commercial use. in 2016 IEEE SENSORS. IEEE, pp. 1-3, IEEE Sensors 2016, Orlando, United States, 30/10/16. https://doi.org/10.1109/ICSENS.2016.7808789

\section{General rights}

Copyright and moral rights for the publications made accessible in the public portal are retained by the authors and/or other copyright owners and it is a condition of accessing publications that users recognise and abide by the legal requirements associated with these rights.

Take down policy

If you believe that this document breaches copyright please view our takedown policy at https://edshare.gcu.ac.uk/id/eprint/5179 for details of how to contact us. 


\section{Towards a Novel Optical Trace Oxygen Sensor for Commerical Use}

\author{
G.R. McDowell*, F.G. Farrow, \\ M. Uttamlal, A.S. Holmes-Smith \\ School of Engineering \& Built Environment \\ Glasgow Caledonian University \\ Glasgow, UK \\ gary.mcdowell@gcu.ac.uk
}

\author{
C. Mitchell, P. H. Shannon \\ SST Sensing Ltd \\ Coatbridge, UK \\ www.sstsensing.com
}

\begin{abstract}
This paper presents the development of a novel luminescence-based trace oxygen sensor that will eventually lead to the production of a commercial sensor for use in gaseous sensing applications. The proprietary sensing formulation provides the means of a robust and stable sensor using a metalloporphyrin complex as the luminescent indicator that is efficiently quenched by oxygen. The spectroscopic properties of the oxygen sensitive layer have been carried out and appropriate optical components and electronics sourced and built into a low cost, compact, miniaturized device. This novel oxygen sensor operates in the 0-10,000 parts per million ( $\mathrm{ppm}$ ) range and offers an alternative to traditional trace oxygen sensors, such as galvanic electrochemical, zirconia and other luminescence-based ppm sensors.
\end{abstract}

Keywords-Gas sensor, luminescence quenching, trace oxygen

\section{INTRODUCTION}

Oxygen $\left(\mathrm{O}_{2}\right)$ is one of the most important chemical species and is vital for the survival of most living organisms [1]. However, in applications such as nitrogen $\left(\mathrm{N}_{2}\right)$ generation, industrial gas manufacturing and food packaging there is a need to ensure $\mathrm{O}_{2}$ is absent, even at the lowest concentration levels. Therefore, trace $\mathrm{O}_{2}$ parts per million (ppm) sensors have been developed with the most common technologies summarised in Table 1.

TABLE I. SUMMARY OF TECHNOLOGIES USED FOR TRACE OXYGEN SENSING.

\begin{tabular}{|l|c|c|c|}
\hline \multirow{2}{*}{ Property } & \multicolumn{3}{|c|}{ Technology } \\
\cline { 2 - 4 } Cost & Electrochemical & Zirconia & Paramagnetic \\
\hline $\begin{array}{l}\text { Operating } \\
\text { temperature }\left({ }^{\circ} \mathrm{C}\right)\end{array}$ & -20 to +55 & High & High \\
\hline $\begin{array}{l}\text { Calibration } \\
\text { intervals }\end{array}$ & $6-12$ months & $\sim 1$ year & $>1$ year \\
\hline Life & $2-3$ years & $>5$ years & $>5$ years \\
\hline
\end{tabular}

Electrochemical sensors are the most widely used as they are low cost, small, accurate and have a reasonable operational lifetime. However, they suffer from long recovery times and deplete when exposed to ambient $\mathrm{O}_{2}$ (air) thus calibration and/or replacement is required periodically. Zirconia and Paramagnetic sensors offer longer operational lifetimes however, they are expensive and Zirconia sensors require a high temperature for operation. The conventional method is the Clark Electrode [2] but $\mathrm{O}_{2}$ is consumed, prone to electrical interferences and has a limited operational lifetime. Clark-type microelectrodes have been developed but they are expensive to fabricate, fragile and their usefulness is limited. [3]. For applications where these considerations are important, optical methods, in particular, luminescence-based trace $\mathrm{O}_{2}$ sensors have been developed commercially by Aanderaa, Centec, PreSens and Pyro Science to name a few.

It is well known that $\mathrm{O}_{2}$ is an efficient quencher of luminescence [4]. Luminescence-based sensing is now regarded as one of the best techniques for $\mathrm{O}_{2}$ sensing [5] due to high detection sensitivity, no analyte consumption and there are a vast array of luminescent indicators and sensing platforms that can be selected to suit the desired application [6]. The luminescence emission intensity and/or excited state lifetime (decay time) of a luminescent indicator is related to $\mathrm{O}_{2}$ concentration through the Stern-Volmer equation:

$$
\frac{I_{0}}{I}=\frac{\tau_{0}}{\tau}=1+K_{S V} \cdot p p O_{2}=1+k_{q} \tau_{0} \cdot p p O_{2}
$$

where $I_{0}, I, \tau_{0}$ and $\tau$ are the luminescence intensity and decay time in the absence and presence of the quencher respectively. $k_{q}$ is the biomolecular quenching constant, $\mathrm{ppO}_{2}$ is the partial pressure of oxygen and $K_{S V}$ is the Stern-Volmer quenching constant. Plots of $I_{0} / I$ and $\tau_{0} / \tau$ versus $\mathrm{O}_{2}$ concentration should yield a straight line. In many cases the line deviates from linearity which indicates that the luminophore exists in more than one environment and/or dynamic and static quenching are occurring concurrently. In these cases, nonlinear forms of the Stern-Volmer equation have been proposed [7], [8].

SST currently market a luminescence-based $\mathrm{O}_{2}$ sensor (LuminOx) which measures $\mathrm{O}_{2}$ in the $0-25 \%$ range or 0-300 mBar $\mathrm{ppO}_{2}$ and can measure $\mathrm{O}_{2}$ in environments where the temperature range is $-30{ }^{\circ} \mathrm{C}$ to $+60{ }^{\circ} \mathrm{C}$. This is achieved through an extensive calibration process. Here, a new development of the LuminOx sensor for trace $\mathrm{O}_{2}$ measurement is described. The aim is to manufacture a low cost, small and robust gaseous oxygen sensor for this market place which is capable of operating for more than 5 years. The luminescent indicator within a proprietary polymer formulation will be 
changed from a ruthenium complex to a metalloporphyrin complex to ensure good sensitivity to low concentrations of $\mathrm{O}_{2}$. Also, the sensor will be developed to have a working temperature range of -30 to $+60{ }^{\circ} \mathrm{C}$ which is an improvement on other commercially available luminescence-based trace $\mathrm{O}_{2}$ sensors which tend to operate from -5 to $50^{\circ} \mathrm{C}$.

\section{EXPERIMENTAL}

All chemicals, reagents and polymers were purchased from commercial suppliers and were used as received. The new $\mathrm{O}_{2}$ sensitive layer is based on the luminescent metalloporphyrin complex Platinum (II) 5,10,15,20-Tetrakis(2,3,4,5,6pentafluorophenyl)-porphyrin (PtTFPP) immobilised within a proprietary sensing formulation.

\section{A. LuminOx Sensor Design for Trace Oxygen}

The $\mathrm{O}_{2}$ sensitive layer is embedded within a miniaturised (18 x $20 \mathrm{~mm})$, compact, optical housing shown in Fig. 1. The sensing layer is deposited onto a $600 \mathrm{~nm}$ cut-on dichroic mirror and fixed within an optical carrier (Fig. 1(a)) at an angle of incidence (AOI) of $45^{\circ}$. In the same carrier, a UV blocking 535 $\mathrm{nm}$ bandpass filter is inserted at AOI $0^{\circ}$ that sits directly in front of a $535 \mathrm{~nm}$ green LED (Fig. 1(b)) connected to a customised printed circuit board (PCB) containing a photodiode that collects the luminescence signal passing through the dichroic mirror. The PCB also contains temperature and pressure sensors so that measurements can be corrected for changes in the luminescence response due to these environmental variables. The optical carrier is fixed on top of the PCB (Fig. 1(c)). For the current LuminOx sensor a housing is added containing an oleophobic and hydrophobic PTFE membrane (Fig. 1(d)) and for trace $\mathrm{O}_{2}(\mathrm{ppm})$ sensing a flow through housing is fixed into place (Fig. 1(e)).
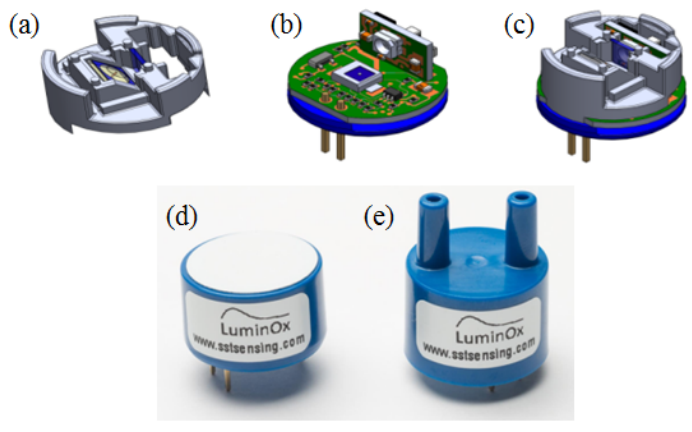

Fig. 1. (a)-(c) LuminOx optical design, (d) current product and (e) new trace $\mathrm{O}_{2}$ sensor housing (see text for explanation).

\section{B. Spectroscopic and Sensor Characterisation}

Spectroscopic characterization of the sensing polymer was carried out on commercial spectrometers prior to insertion into the LuminOx sensor. Luminescence excitation and emission spectra were collected using a HORIBA Jobin Yvon Ltd FluoroMax-3 spectrophotometer. Luminescence lifetime (decay time) measurements were carried out on a HORIBA Jobin Yvon 5000U lifetime instrument using either Multichannel scaling (MCS) and/or Time-correlated single photon counting (TCSPC) depending on $\mathrm{ppO}_{2} . \mathrm{O}_{2}$ and $\mathrm{O}_{2}$ free nitrogen (OFN) gases were purchased from BOC gases. An Environics Series 2020 computerized gas dilution system was used to control the concentration of $\mathrm{O}_{2}$. A factory calibrated SST LuminOx (0-300 mBar $\left.\mathrm{ppO}_{2}\right)$ sensor was used as a reference. Trace oxygen measurements were carried out by characterizing the luminescence decay time of the sensing matrix to changes with $\mathrm{O}_{2}$ concentration from $0-10,000 \mathrm{ppm}$ using the gas blender to mix a cylinder of $98.7 \% \mathrm{~N}_{2} / 1.3 \% \mathrm{O}_{2}$ or $>99.98 \% \mathrm{~N}_{2} / 130$ ppm $\mathrm{O}_{2}$ with OFN.

\section{RESULTS}

\section{A. Oxygen Sensor Characterisation}

The metalloporphyrin complex PtTFPP has an intensely absorbing Soret-band ( $\sim 390 \mathrm{~nm}$ ) corresponding to an $\mathrm{S}_{0} \rightarrow \mathrm{S}_{2}$ transition and weaker absorbing Q-bands $(\sim 504 \mathrm{~nm}$ and $\sim 538 \mathrm{~nm}$ ) corresponding to $\mathrm{S}_{0} \rightarrow \mathrm{S}_{1}$ transitions in the visible spectrum [6]. When illuminating PtTFPP continuously for 1 hour at $\lambda_{\mathrm{ex}}=390 \mathrm{~nm}$ and $\lambda_{\mathrm{ex}}=535 \mathrm{~nm}$ in air $\left(207 \mathrm{mBar} \mathrm{ppO}_{2}\right)$ the luminescence intensity dropped by $0.036 \pm 0.010 \%$ and $0.003 \pm 0.002 \%$ at each wavelength respectively. Therefore, the rate of photodegradation of PtTFPP was reduced 10-fold when $\lambda_{\text {ex }}=535 \mathrm{~nm}$. Importantly, bright LEDs emitting at this wavelength are readily available. The \% photodegradation is a marked improvement on that observed for the same luminescent indicator in other sensing matrices where $\lambda_{\text {ex }}=540 \mathrm{~nm}$ [9]. The longer excitation wavelength ensures that PtTFPP is less reactive in the excited state due to the $\mathrm{S}_{0} \rightarrow \mathrm{S}_{1}$ transition. In addition, it has also been suggested that PtTFPP exhibits excellent photostability due to the presence of the strongly electron-withdrawing character of the pentafluorophenyl substituents. The sensing formulation in this work contains a fluoropolymer which may further enhance the photostability. This renders PtTFPP less reactive toward oxidation by singlet oxygen and prolongs the life of the luminescent indicator [9].

The luminescence decay time of PtTFPP in the sensing matrix in the absence of $\mathrm{O}_{2}\left(\tau_{0}\right)$ and at ambient temperature was $83.5 \mu$ s and dropped to $1.1 \mu$ s in air $\left(201 \mathrm{mBar}_{\mathrm{ppO}}\right)$. The Stern-Volmer plots (SVPs) of the PtTFPP sensor and the LuminOx sensor are shown in Fig. 2. Comparing the sensitivity shows that the PtTFPP sensor is 9 times more sensitive as the Stern-Volmer quenching constants $\left(K_{S V}\right)$ were $0.3893 \pm 0.0066$ $\mathrm{mBar}^{-1}\left(\mathrm{R}^{2}=0.9997\right)$ and $0.0433 \pm 0.0015 \mathrm{mBar}^{-1}$ $\left(\mathrm{R}^{2}=0.9986\right)$ for the PtTFPP sensor and the LuminOx sensor respectively.

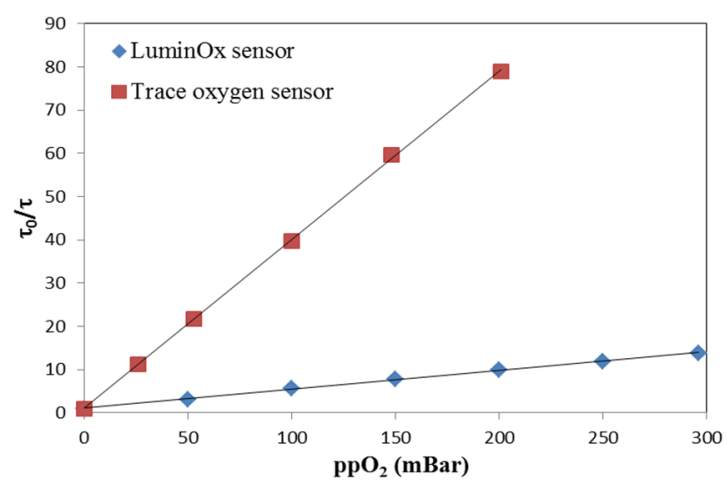

Fig. 2. Stern-Volmer plots of $\tau_{0} / \tau$ versus $\mathrm{ppO}_{2}$ for the SST LuminOx sensor $\left(\lambda_{\mathrm{ex}}=440 \mathrm{~nm}, \lambda_{\mathrm{em}}=590 \mathrm{~nm}\right)$ and the new trace $\mathrm{O}_{2}$ sensor $\left(\lambda_{\mathrm{ex}}=375 \mathrm{~nm}, \lambda_{\mathrm{em}}=645 \mathrm{~nm}\right)$ at ambient temperature. 


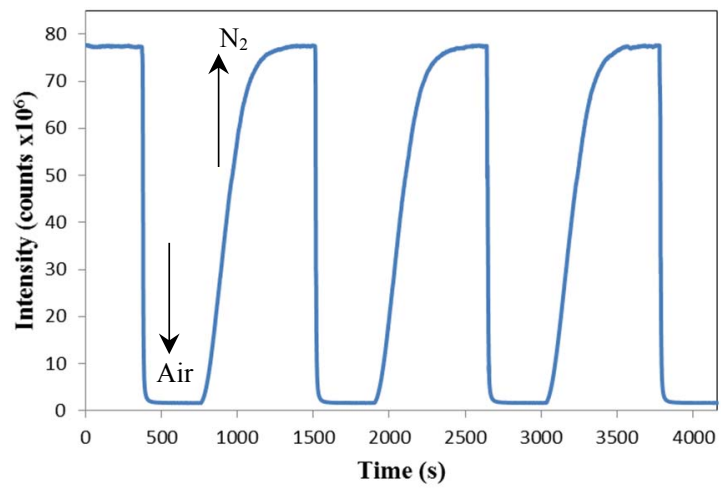

Fig. 3. Luminescence intensity response of the PtTFPP $\mathrm{O}_{2}$ sensor when switching between nitrogen $\left(\mathrm{N}_{2}\right)$ and air $\left(207 \mathrm{mBar}_{\mathrm{ppO}}\right)$. $\lambda_{\text {ex }}=535 \mathrm{~nm}, \lambda_{\mathrm{em}}=645 \mathrm{~nm}$.

Fig. 3 shows the luminescence intensity response of PtTFPP in the polymer matrix in going from $\mathrm{N}_{2}$ to air (207 mBar $\mathrm{ppO}_{2}$ ) and back for several cycles on the commercial luminescence spectrophotometer. Critically, the luminescence intensity was reversible and highly repeatable when switching between $\mathrm{N}_{2}$ and air, indicating that the sensor is unaffected by exposure to ambient $\mathrm{O}_{2}$, an advantage over electrochemical ppm sensors as they deplete with time when exposed to ambient $\mathrm{O}_{2}$. Within the LuminOx system, the $\mathrm{T}_{90}$ (increase or decrease of luminescence signal to $90 \%$ of its original value) response and recovery times were $13.9 \pm 0.5 \mathrm{~s}$ and $23.9 \pm 0.8 \mathrm{~s}$ respectively. It should be noted that the response and recovery time of a luminescent indicator is not only affected by the permeability of the polymer matrix to $\mathrm{O}_{2}$ but is also dependent on the thickness of the sensing layer. In this work, the sensing layer was $\sim 500 \mu \mathrm{m}$. Decreasing the thickness of the sensing layer will result in a faster response and recovery time due to faster equilibration of $\mathrm{O}_{2}$ through the polymer matrix.

\section{B. Trace Oxygen Analysis}

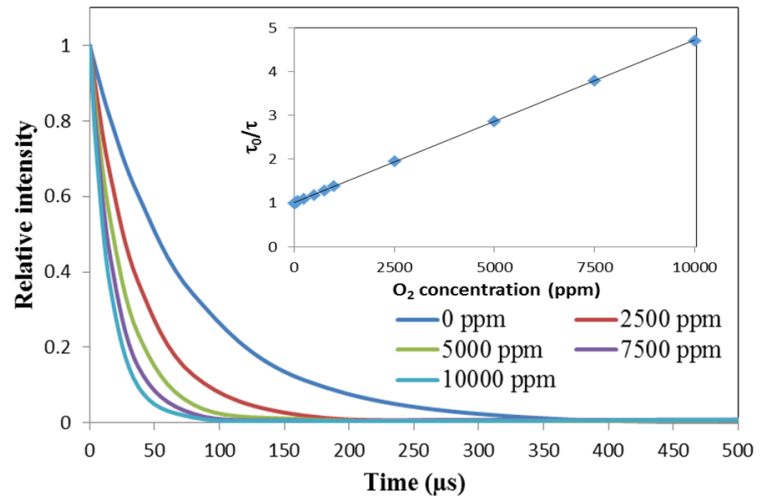

Fig. 4. Decay time of the sensor with increasing $\mathrm{O}_{2}$. Note that ppm can also be expressed as $\mu$ Bar. Inset is a Stern-Volmer plot of $\tau_{0} / \tau$ versus $\mathrm{O}_{2}$ concentration.

The decay time of PtTFPP in the absence of $\mathrm{O}_{2}\left(\tau_{0}\right)$ was $85.6 \mu \mathrm{s}$ and decreased with increasing $\mathrm{O}_{2}$ shown in Fig. 4 to $18.2 \mu$ s at $10,000 \mathrm{ppm}$ thus $\tau_{0} / \tau=4.71$ (Fig. 4 inset). A linear correlation $\left(\mathrm{R}^{2}=0.9999\right)$ between $\tau_{0} / \tau$ and ppm was observed over the wide $\mathrm{O}_{2}$ ppm concentration range, (Fig. 4 inset) beneficial for calibration of the sensor. Going from $0 \mathrm{ppm}$ to
$25 \mathrm{ppm}_{2}$ caused the decay time of PtTFPP to drop $\sim 0.9 \mu \mathrm{s}$ demonstrating the high sensitivity of the sensor to changes in $\mathrm{O}_{2}$. Preliminary tests were also conducted in an $\mathrm{O}_{2}$ free environment at $-30{ }^{\circ} \mathrm{C}$ and $+60{ }^{\circ} \mathrm{C}$ with decay times of PtTFPP being $100.5 \mu \mathrm{s}$ and $62.9 \mu$ s respectively to determine the sensitivity and usefulness of the sensor to changes with temperature.

\section{CONCLUSIONS \& FURTHER WORK}

A novel luminescence-based trace $\mathrm{O}_{2}$ sensor has been described that will lead to the production of a commercial product for SST. The sensor will be able to compete within the market (Table 1) and will offer an attractive alternative to these commercial trace $\mathrm{O}_{2}$ sensors as it will be low cost, robust, compact and does not deplete when exposed to ambient $\mathrm{O}_{2}$.

Most commercial luminescence-based trace $\mathrm{O}_{2}$ sensors are used in the detection of dissolved oxygen (DO) thus have been developed to detect parts per billion (ppb) as well as ppm. One drawback is their operating temperature range which tends to be -5 to $+50{ }^{\circ} \mathrm{C}$. In addition, the life of most luminescencebased trace $\mathrm{O}_{2}$ sensors is $\sim 3$ years if stored in the dark and under ambient conditions. The aim is to improve on these aspects with the new trace $\mathrm{O}_{2}$ sensor i.e. -30 to $+60{ }^{\circ} \mathrm{C}$ and $>5$ years life under continuous operation. Also, the majority of trace $\mathrm{O}_{2}$ sensors are opt(r)ode devices. The new LuminOx is unique as it is a compact, complete, miniaturized device thus no additional electronics or accessories are required.

Further work is underway to determine the repeatability of the PtTFPP based trace $\mathrm{O}_{2}$ sensor over the full temperature $\left(-30\right.$ to $\left.+60{ }^{\circ} \mathrm{C}\right)$ and $\mathrm{O}_{2}$ concentration range $(0-10,000 \mathrm{ppm})$. This will include rigorous photo- and long-term stability tests to determine the longevity of the sensor.

\section{REFERENCES}

[1] X. Wang and O. S. Wolfbeis, "Optical methods for sensing and imaging oxygen: materials, spectroscopies and applications.," Chem. Soc. Rev., vol. 43, pp. 3666-3761, 2014.

[2] L. C. Clark, "Monitoring and control of blood and tissue oxygen tensions," Transactions American Society for Artificial Internal Organs, vol. 2. pp. 41-57, 1956.

[3] C. C. Wu, T. Yasukawa, H. Shiku, and T. Matsue, "Fabrication of miniature Clark oxygen sensor integrated with microstructure," Sensors Actuators B, vol. 110, no. 2, pp. 342-349, 2005.

[4] J. Lakowicz, Principles of Fluorescence Spectroscopy, 3rd ed. New York: Springer, 2006.

[5] O. S. Wolfbeis, "Luminescent sensing and imaging of oxygen: Fierce competition to the Clark electrode," BioEssays, vol. 37, pp. 921-928, 2015.

[6] M. Quaranta, S. M. Borisov, and I. Klimant, "Indicators for optical oxygen sensors," Bioanal. Rev., vol. 4, pp. 115-157, 2012.

[7] J. R. Bacon and J. N. Demas, "Determination of Oxygen Concentrations by Luminescence Quenching of a Polymer- Immobilized TransitionMetal Complex," Am. Chem. Soc., vol. 59, no. 23, pp. 2780-2785, 1987.

[8] E. R. Carraway, J. N. Demas, B. A. DeGraff, and J. R. Bacon, "Photophysics and Photochemistry of Oxygen Sensors Based on Luminescent Transition-Metal Complexes," Anal. Chem., vol. 63, pp. 337-342, 1991.

[9] S.-K. Lee and I. Okura, "Photostable Optical Oxygen Sensing Material: Platinum Tetrakis(pentafluorophenyl)porphyrin Immobilized in Polystyrene," Anal. Commun., vol. 34, no. 6, pp. 185-188, 1997. 